\title{
Cost effectiveness of extended treatment with low molecular weight heparin (dalteparin) in unstable coronary artery disease: results from the FRISC II trial
}

\author{
M Janzon, L-Å Levin, E Swahn, and the FRISC II Investigators*
}

Heart 2003;89:287-292

\begin{abstract}
Background: In unstable coronary artery disease short term treatment with low molecular weight heparin in addition to aspirin has been shown to be effective.

Objective: To assess the cost effectiveness of extended treatment with dalteparin in patients managed with a non-invasive treatment strategy.

Design: Prospective, randomised, multicentre study.

Setting: 58 centres in Sweden, Denmark, and Norway, of which 16 were interventional.

Patients: After at least five days' treatment with open label dalteparin, 2267 patients were randomised to continue double blind treatment with either subcutaneous dalteparin twice daily or placebo for three months. The patients' use of health service resources was recorded prospectively. Main outcome measure: Death/myocardial infarction.

Results: After one month into the double blind period there was a $47 \%$ relative reduction in death or myocardial infarction in the dalteparin group compared with the placebo group $(p=0.002)$. There was a non-significant mean cost difference, favouring the placebo group, of 849 Swedish crowns (SEK) per patient (equivalent to $£ 58$ ). The incremental cost effectiveness ratio for giving dalteparin treatment for one month was SEK 30300 (range -78000 to 139000 ) (£2060, range - £5300 to £9400) per avoided death or myocardial infarct. At three months, the decrease in death or myocardial infarction was not significant, precluding cost effectiveness analyses.

Conclusions: There is a marginal and non-significant increase in costs for one month of extended dalteparin treatment compared with placebo. Extended dalteparin treatment lowers the risk of death or myocardial infarction in patients with unstable coronary artery disease. While in many countries the resources for early intervention are limited, extended dalteparin treatment up to one month is a cost effective bridge to invasive intervention.
\end{abstract}

See end of article for authors' affiliations

Correspondence to: Dr Magnus Janzon, Department of Cardiology, Linköping Heart Centre, University Hospital, SE-58 1 85 Linköping, Sweden; magnus.janzon@imv.liu.se

*The FRISC II investigators and committee members are listed in the appendix.

Accepted 2 October 2002

$\mathrm{T}$ he efficacy of short term treatment with subcutaneous low molecular weight heparin in addition to aspirin in reducing death and myocardial infarction in patients with unstable coronary artery disease has been demonstrated in several trials..$^{1-3}$ However, the optimal duration of this combination treatment has yet to be resolved. ${ }^{4}$ Thrombi at the coronary lesion and increased coagulation activity persist for months after an episode of instability. ${ }^{5-7}$ The risk of adverse cardiac events is increased during this period. ${ }^{1-3} 8-11$

In the FRISC (Fragmin and fast revascularisation during instability in coronary artery disease) trial, ${ }^{1}$ extended treatment with the low molecular weight heparin dalteparin resulted in additional protection against cardiac events in patients at higher risk-that is, patients with raised troponin $\mathrm{T}$ concentrations - who had a very low rate of early invasive procedures. $^{12}$ Thus the effects of long term antithrombotic treatment in unstable coronary artery disease may be dependent on the patient population and on the proportion of patients treated with early invasive procedures.

An economic assessment of short term treatment with the low molecular weight heparin enoxaparin versus unfractionated heparin in patients with unstable coronary artery disease has been carried out. ${ }^{13}$ It was found that treatment with enoxaparin improved clinical outcomes and cost less than treatment with standard unfractionated heparin.

Pharmacoeconomic analyses of dalteparin carried out in patients requiring treatment for established thromboembolic disease showed that there were cost advantages with dalteparin over unfractionated heparin from a hospital perspective. ${ }^{14}$ Cost effectiveness studies of dalteparin treat- ment in unstable coronary artery disease have not been conducted to date, and there are no cost effectiveness studies comparing extended treatment with low molecular weight heparin versus placebo. The FRISC II invasive trial ${ }^{15}{ }^{16}$ showed that an early invasive strategy is beneficial, especially in high risk patients. However, catheterisation laboratory capacities and resources are limited. Not all patients can get the benefit of this early approach. There is wide variation in the use of invasive procedures in Europe as well as in North America. ${ }^{17}{ }^{18}$ In many countries, especially in general practice hospitals and in smaller hospitals, the waiting time for catheterisation and revascularisation is many weeks. ${ }^{17}$

The aim of this prospective study was to evaluate the cost and medical efficacy of extended treatment for one and three months with dalteparin compared with placebo in patients randomised to a non-invasive treatment strategy. We report the cost effectiveness of extended dalteparin treatment using data gathered during the FRISC II study.

\section{METHODS}

\section{Study design}

The FRISC II medical trial design has been published previously. ${ }^{19}$ In brief, it was a prospective, randomised multicentre trial with parallel groups. There were 58 Scandinavian centres in the study, of which 16 were interventional. The comparison of extended dalteparin treatment with placebo was double blind. Patients were eligible for inclusion if they had symptoms of ischaemia that were increasing or occurring at rest, or if suspicion of acute myocardial infarction 
was warranted, with the last episode preceding the first dose of dalteparin or standard heparin by less than 48 hours. Myocardial ischaemia was always verified by ECG (ST depression or T wave inversion) or by biochemical markers.

The exclusion criteria were: an increased risk of bleeding or anaemia; an indication for thrombolysis or thrombolytic treatment given during the preceding 24 hours; angioplasty within the previous six months; being on the waiting list for coronary revascularisation procedures; other acute or severe cardiac disease; renal or hepatic insufficiency; known clinically relevant osteoporosis; other severe illness; hypersensitivity to randomised drugs; and anticipated problems concerning cooperation or participation in this or another clinical trial. There was no upper age limit.

Within 72 hours after the start of open label dalteparin (or standard heparin) the patients were randomised, using stratification by centre, to extended dalteparin or extended placebo. All patients received basic treatment with aspirin and at least five days of subcutaneous dalteparin (120 IU/kg every 12 hours) before they continued with the randomised treatment with twice daily subcutaneous injections of either dalteparin or placebo. Women weighing less than $80 \mathrm{~kg}$ and men weighing less than $70 \mathrm{~kg}$ received dalteparin $5000 \mathrm{IU}$ twice daily; above these weight limits the dalteparin dose was 7500 IU twice daily. This treatment was continued for a period of three months, with patients self injecting by prefilled single dose syringes after discharge from hospital. Follow up was done in hospital, by telephone after two weeks, and by outpatient visits after six weeks and three months. The primary end points were death or myocardial infarction during the double blind period.

\section{Use of resources}

For all patients in the study we logged their consumption of health care resources prospectively in the main case report form, from the first day of double blind treatment until the three month follow up. The direct medical costs were categorised as hospital admissions, investigations, interventions, pharmaceuticals, and outpatient care. In this study we used a health care provider perspective.

\section{Hospital admissions}

The number of days for hospital admission (all reasons) was recorded. This included care in the intensive care unit/cardiac care unit (ICU/CCU), cardiology/internal medicine ward, thoracic surgery ICU, thoracic surgery ward, and general ward.

\section{Investigations and interventions}

The recorded investigations were exercise tests, echocardiograms, and coronary artery catheterisations. The predefined interventions were percutaneous transluminal coronary angioplasty with and without stenting, and coronary artery bypass grafting.

\section{Pharmaceuticals}

Pharmacological treatments including the use of thrombolytic agents (streptokinase, alteplase, and reteplase), glycoprotein IIb/IIIa blockade (abciximab), and dalteparin were recorded.

\section{Outpatient care}

Outpatient hospital visits and home care visits involving a physician, nurse, or physiotherapist were noted by the patients in a questionnaire.

\section{Costing}

To obtain the actual prices for the hospital admissions, investigations, and interventions, a costing study was conducted in 1997 at all 36 participating Swedish centres, which comprised over $80 \%$ of all patients in the trial. The hospitals in this study adequately represented the different categories of hospital in
Table 1 Prices employed to value resource use

\begin{tabular}{lc}
\hline Resource & Price (SEK) \\
\hline Hospital admissions (per day) & \\
ICU/CCU & 5560 \\
Cardiology/medical ward & 3335 \\
Thoracic surgery ICU & 19990 \\
Other wards & 3335 \\
& \\
Investigations (per procedure) & \\
Exercise test & 1005 \\
Echocardiogram & 1225 \\
Coronary catheterisation & 12380 \\
& \\
Interventions (per procedure) & \\
PTCA without stent & 41875 \\
PTCA with stent & 51840 \\
CABG & 96030 \\
& \\
Pharmaceuticals (per treatment episode) & \\
Streptokinase & 950 \\
Alteplase & 9530 \\
Reteplase & 9495 \\
Abciximab & 9815 \\
Intervention treatment* & \\
Dalteparin (10 00O IU) & 71 \\
Dalteparin (15 00O IU) & 113 \\
Outpatient care & \\
Visit to physician & \\
Visit to nurse & \\
Visit to physiotherapist & \\
Physician home visit & 305 \\
Nurse home visit & 305 \\
\hline *Prices for intervention treatment are per day. \\
CABG, coronary artery bypass graft; CCU, cardiac care unit; ICU, \\
intensive care unit; PTCA, percutaneous transluminal coronary \\
angioplasty. \\
\end{tabular}

Scandinavia, ranging from small county hospitals to university hospitals. The price for an inpatient day in hospital was based on the annual cost of running the ward, including physicians' fees, divided by the number of bed occupancy days over the year (table 1).

The prices of pharmacological treatment were collected from pharmacy prices in Sweden. ${ }^{20}$ The price per visit to a physician, a nurse, and a physiotherapist (including home visits) was obtained from nine hospitals in south eastern Sweden. ${ }^{21}$

Costs were inflated to year 2000 prices using the consumer price index (CPI) 2000. The inflation factor between 1997 and 2000 was $1.1 \%{ }^{22}$ ( $£ 1$ was equivalent to 14.71 Swedish crowns (SEK) on 14 March 2002). ${ }^{23}$

\section{Analyses and statistics}

Analyses of clinical outcome and costs were on an intention to treat basis. ${ }^{19}$ All costs were expressed as current costs, and no discount rate was used because the follow up period was less than one year.

Cost analysis was based on resource use recorded after the start of the double blind treatment until the three month follow up, or until death within three months. Following the clinical study ${ }^{19}$ we made an additional analysis at one month. The prices we used in the analyses indicate the cost of treating a patient and are not charges or payments but reflect opportunity costs. ${ }^{24}$ The hospitals' median average prices were used as estimates for the real unit costs, and these were later tested in a sensitivity analysis.

We used $t$ tests to compare the treatment groups in terms of mean costs. This method is known to be fairly robust with respect to non-normality, especially if the sample size is as large as in this study..$^{25}$ The clinical results are presented as odds ratios with $95 \%$ confidence intervals. Data processing 


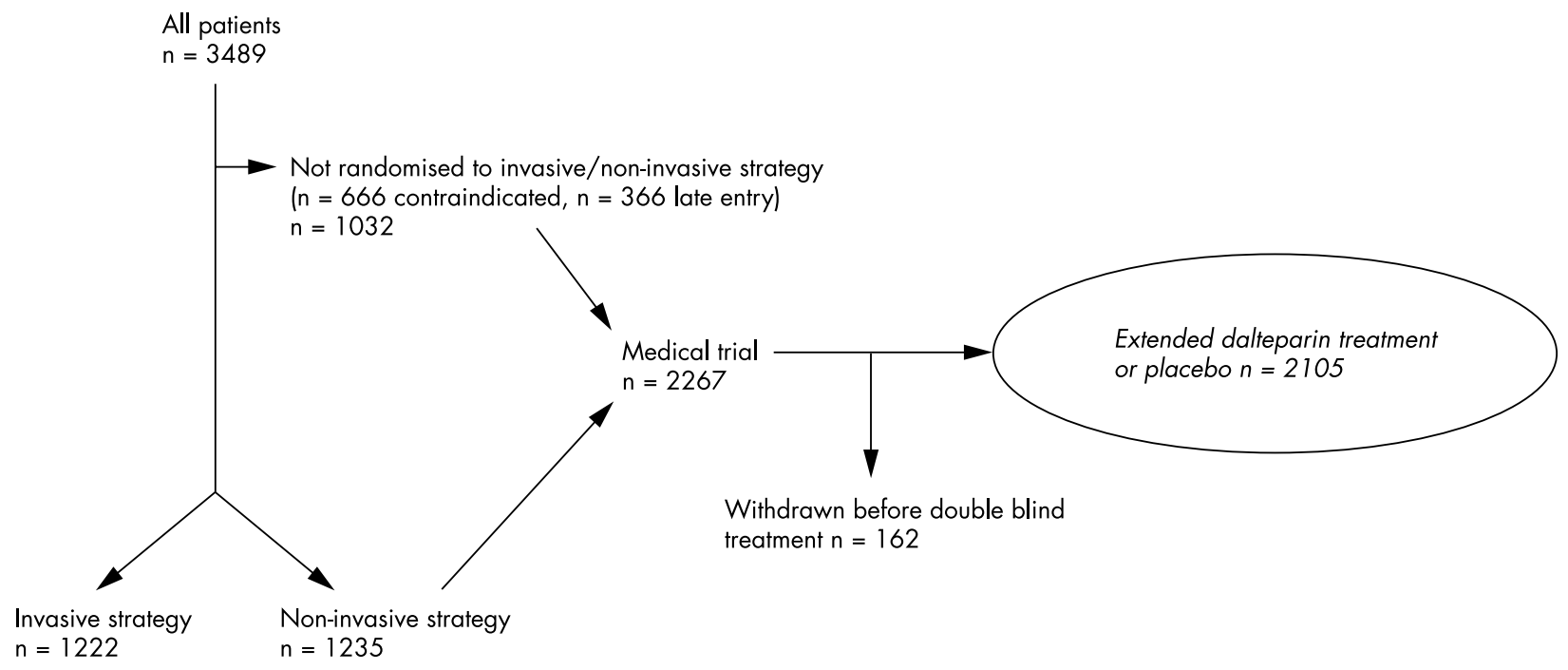

Figure 1 Disposition of the patients in the FRISC II study.

was undertaken independently in the Department of Biostatistics and Data Management, Pharmacia Corporation, Sweden, and by us. All our own statistical analyses were done using the SPSS 10.1 statistical programs for personal computers.

\section{Data management, quality, and ethics}

The trial was run according to good clinical practice. The quality of the data was ensured by continuous source data verification of all case report forms by external monitors employed by the sponsoring pharmaceutical company. All cardiac events (efficacy end points) were sent to the independent end point adjudication committee, and adverse events were also continuously sent directly from the centres to the Data and Safety Monitoring Board. Randomisation was done by telefax contact with an independent organisation (Clinical Data Care, Lund, Sweden). The study complied with the Declaration of Helsinki and all local ethics committees approved the protocol.

\section{RESULTS}

Patients

Between June 1996 and August 1998, 2267 patients were randomised to extended dalteparin treatment or placebo. Of these, 1235 constituted the non-invasive part of the invasive/ non-invasive randomisation. Also included in the non-invasive (medical treatment) arm of the trial were 366 patients who were included late, after the recruitment period for the invasive and non-invasive comparison, and 666 patients who had contraindications to invasive treatment. Of the 2267 patients who entered the medical treatment arm, 162 were withdrawn before the double blind treatment period (fig 1).

\section{Baseline characteristics}

There were no significant differences in baseline characteristics between the two groups (table 2). The median age was 67 years and $68 \%$ of the participants were men. A majority of the patients could be considered at high risk: $81 \%$ had chest pain at rest; $59 \%$ had elevation of troponin $\mathrm{T}(\geqslant 0.1 \mu \mathrm{g} / \mathrm{l})$ and, at entry, 48\% showed ST segment depression on ECG. However, the majority of patients had normal left ventricular function.

\section{Costs: one month follow up}

For both treatment arms, $4 \%$ of the patients were admitted to hospital during the first month. There were no significant differences between the measured variables in the dalteparin group and the placebo group after one month of double blind treatment (table 3). While the cost of intervention with dalteparin for one month was significantly greater than the cost for the placebo group, the overall cost of resources per patient in the dalteparin group did not differ significantly from the placebo group. The mean difference for the first month was SEK 849 (£58) per patient.

\section{Costs: three months follow up}

A detailed breakdown of the number of events and direct medical costs per patient is given in tables 4 and 5, respectively. Both groups of patients spent on average four days in hospital. Patients treated with dalteparin had a significantly lower need for exercise tests but the need for echocardiograms and coronary catheterisation was similar in the two groups. There were no significant differences in total costs for investigations.

The duration of double blind treatment was similar in the dalteparin and placebo groups (table 4). Two thirds of the

Table 2 Baseline characteristics of the double blind treatment groups

\begin{tabular}{|c|c|c|}
\hline Variable & $\begin{array}{l}\text { Dalteparin } \\
(n=1049)\end{array}$ & Placebo $(n=1056)$ \\
\hline Age (years), median (range) & 67 (37-91) & $67(38-87)$ \\
\hline Male/female (\%) & $68 / 32$ & $69 / 31$ \\
\hline \multicolumn{3}{|l|}{ Coronary risk factors } \\
\hline Hypertension & $33 \%$ & $33 \%$ \\
\hline Cholesterol $>5.5 \mathrm{mmol} / /$ & $53 \%$ & $57 \%$ \\
\hline Current smoker & $25 \%$ & $27 \%$ \\
\hline Diabetes mellitus & $14 \%$ & $12 \%$ \\
\hline \multicolumn{3}{|c|}{ Previous and current cardiac disease } \\
\hline Previous $\mathrm{MI}$ & $30 \%$ & $27 \%$ \\
\hline Previous PTCA & $4 \%$ & $4 \%$ \\
\hline Previous CABG & $14 \%$ & $13 \%$ \\
\hline Angina $>48 \mathrm{~h}$ & $70 \%$ & $70 \%$ \\
\hline Chest pain at rest & $82 \%$ & $80 \%$ \\
\hline ST depression at entry & $46 \%$ & $50 \%$ \\
\hline Troponin $T \geqslant 0.1 \mu \mathrm{g} / /^{*}$ & $57 \%$ & $60 \%$ \\
\hline LVEF $<45 \% \dagger$ & $14 \%$ & $17 \%$ \\
\hline
\end{tabular}

*Blood samples for central troponin T analysis were obtained at randomisation in 999 and 1015 patients, respectively. †Determined echocardiographically in 842 and 860 patients, respectively.

$C A B G$, coronary artery bypass graft; $L V E F$, left ventricular ejection fraction; MI, myocardial infarction; PTCA, percutaneous transluminal coronary angioplasty. 
Table 3 Mean costs (in Swedish crowns) per patient during the first month

\begin{tabular}{lcclc}
\hline Item & $\begin{array}{c}\text { Dalteparin } \\
(\mathrm{n}=1049)\end{array}$ & $\begin{array}{c}\text { Placebo } \\
(\mathrm{n}=1056)\end{array}$ & $\mathrm{p}$ Value & Cl for difference \\
\hline Hospital admissions & 8388 & 8825 & $\mathrm{NS}$ & -2067 to 1193 \\
Investigations & 803 & 973 & $\mathrm{NS}$ & -443 to 103 \\
Interventions & 4013 & 4809 & $\mathrm{NS}$ & -2317 to 725 \\
Pharmaceuticals & 56 & 117 & $\mathrm{NS}$ & -145 to 23 \\
Intervention treatment & 2313 & 0 & $<0.001$ & 2265 to 2359 \\
All costs & $\mathbf{1 5 5 7 3}$ & $\mathbf{1 4 7 2 4}$ & $\mathbf{N S}$ & $\mathbf{- 2 1 9 1}$ to $\mathbf{3 8 8 9}$ \\
\hline $\mathrm{Cl}$, confidence interval. & & & &
\end{tabular}

patients received the higher dose of dalteparin (7500 IU twice daily). The significantly higher total cost for pharmaceuticals for patients treated with dalteparin reflected the per protocol intervention with dalteparin: the difference compared with the placebo group was SEK 7723 (£525) per patient.

The overall costs for three months of extended dalteparin treatment were significantly higher than for placebo. The cost difference was SEK 6739 (£458) per patient.

\section{Clinical end points}

At one month of extended treatment there was a $47 \%$ relative and a $2.8 \%$ absolute reduction in the primary combined end point of death or myocardial infarction in favour of dalteparin $(p=0.002)$. At three months there was a non-significant $19 \%$ relative and $1.3 \%$ absolute reduction in death or myocardial infarction in the dalteparin group. There were nine cardiac deaths in the dalteparin group $(0.9 \%)$ and 16 in the placebo group $(1.5 \%)$.

\section{Cost effectiveness}

Considering a cost increase of SEK 849 (£58) per patient with extended treatment with dalteparin for one month compared with placebo, the incremental cost effectiveness ratio for giving dalteparin treatment for one month after an episode of unstable coronary artery disease was SEK 30300 (£2060) per avoided death or myocardial infarct. Taking the cost confidence interval into consideration, the cost effectiveness ratio of giving dalteparin for one month varied between cost saving of SEK $-78000(-£ 5300)$ and an expense of up to SEK 139000 (£9400) per patient. At the three months follow up the decrease in death or myocardial infarction was not significant, precluding cost effectiveness analyses.

\begin{tabular}{|c|c|c|c|c|c|}
\hline Item & $\begin{array}{l}\text { Dalteparin } \\
(n=1049)\end{array}$ & $\begin{array}{l}\text { Placebo } \\
(n=1056)\end{array}$ & p Value & $\begin{array}{l}\text { Mean } \\
\text { difference }\end{array}$ & $\begin{array}{l}\mathrm{Cl} \text { for the } \\
\text { difference }\end{array}$ \\
\hline \multicolumn{6}{|l|}{ Hospital admissions (days) } \\
\hline ICU/CCU & 0.67 & 0.76 & NS & -0.09 & -0.28 to 0.10 \\
\hline Cardiology/medical ward & 2.39 & 2.23 & NS & 0.16 & -0.29 to 0.61 \\
\hline Thoracic surgery ICU & 0.18 & 0.17 & NS & 0.01 & -0.06 to 0.08 \\
\hline Thoracic surgery ward & 0.57 & 0.58 & NS & -0.01 & -0.20 to 0.18 \\
\hline Other wards & 0.47 & 0.47 & NS & 0.00 & -0.22 to 0.22 \\
\hline All admissions & 4.28 & 4.21 & NS & 0.07 & -0.69 to 0.83 \\
\hline \multicolumn{6}{|l|}{ Investigations } \\
\hline Exercise test & 0.86 & 0.90 & 0.03 & -0.04 & -0.08 to 0.00 \\
\hline Echocardiogram & 0.05 & 0.05 & NS & 0.00 & -0.02 to 0.02 \\
\hline Coronary catheterisation* & 0.13 & 0.15 & NS & -0.02 & -0.05 to 0.01 \\
\hline \multicolumn{6}{|l|}{ Interventions } \\
\hline PTCA without stent & 0.03 & 0.03 & NS & 0.00 & -0.01 to 0.01 \\
\hline PTCA with stent & 0.04 & 0.05 & NS & -0.01 & -0.03 to 0.01 \\
\hline CABG & 0.06 & 0.06 & NS & 0.00 & -0.02 to 0.02 \\
\hline \multicolumn{6}{|c|}{ Pharmaceuticals (treatment episodes) } \\
\hline Streptokinase & $0.004(4)$ & $0.010(10)$ & NS & -0.006 & -0.013 to 0.001 \\
\hline Alteplase & $0.005(5)$ & $0.012(13)$ & NS & -0.007 & -0.016 to 0002 \\
\hline Reteplase & 0.001 (1) & 0.001 (1) & NS & 0.000 & -0.002 to 0.002 \\
\hline Abciximab & $0.006(6)$ & $0.005(5)$ & NS & 0.001 & -0.005 to 0007 \\
\hline \multicolumn{6}{|l|}{ Intervention treatment } \\
\hline $\begin{array}{l}\text { Dalteparin (10 } 000 \text { IU per } \\
\text { day)/placebo }\end{array}$ & 79.3 & 81.6 & NS & -2.3 & -4.6 to 0.0 \\
\hline $\begin{array}{l}\text { Dalteparin (15 } 000 \mathrm{IU} \text { per } \\
\text { day)/placebo }\end{array}$ & 75.8 & 80.2 & 0.024 & -4.4 & -8.1 to -0.7 \\
\hline \multicolumn{6}{|l|}{ Outpatient care } \\
\hline Visits to physician & 3.66 & 3.63 & NS & 0.03 & -0.10 to 0.16 \\
\hline Visits to nurse & 0.85 & 0.91 & NS & -0.06 & -0.21 to 0.09 \\
\hline Visits to physiotherapist & 0.64 & 0.70 & NS & -0.06 & -0.27 to 0.15 \\
\hline Physician home visits & 0.06 & 0.05 & NS & 0.01 & -0.02 to 0.04 \\
\hline Nurse home visits & 0.18 & 0.36 & NS & -0.18 & -0.46 to 0.10 \\
\hline
\end{tabular}

*Coronary catheterisations that led to PTCA ad hoc are listed under interventions. $C A B G$, coronary artery bypass graft; $C C U$, cardiac care unit; $\mathrm{Cl}$, confidence interval; $I C U$, intensive care unit; PTCA, percutaneous transluminal coronary angioplasty. 


\begin{tabular}{|c|c|c|c|c|c|}
\hline Item & Dalteparin $(n=1049)$ & Placebo $(n=1056)$ & $\mathrm{p}$ Value & Mean difference & $\mathrm{Cl}$ for the difference \\
\hline \multicolumn{6}{|l|}{ Hospital admissions (days) } \\
\hline ICU/CCU & 3743 & 4210 & NS & -467 & -1541 to 607 \\
\hline Cardiology/medical ward & 7962 & 7452 & NS & 510 & -988 to 2008 \\
\hline Thoracic surgery ICU & 1927 & 1845 & NS & 82 & -676 to 840 \\
\hline Thoracic surgery ward & 1575 & 1612 & NS & -37 & -576 to 502 \\
\hline Other wards & 1584 & 1576 & NS & 8 & -723 to 739 \\
\hline All admissions & 16791 & 16695 & NS & 96 & -2970 to 3162 \\
\hline \multicolumn{6}{|l|}{ Investigations } \\
\hline Exercise test & 862 & 909 & 0.03 & -47 & -93.6 to -0.4 \\
\hline Echocardiogram & 64 & 58 & NS & 6 & -21.6 to 33.6 \\
\hline Coronary catheterisations* & 1640 & 1852 & NS & -212 & -580 to 156 \\
\hline All investigations & 2566 & 2819 & NS & -253 & -622 to 116 \\
\hline \multicolumn{6}{|l|}{ Interventions } \\
\hline PTCA without stent & 1158 & 1388 & NS & -230 & -920 to 460 \\
\hline PTCA with stent & 2224 & 2504 & NS & -280 & -1205 to 645 \\
\hline CABG & 5950 & 6184 & NS & -234 & -2232 to 1764 \\
\hline All interventions & 9332 & 10076 & NS & -744 & -3009 to 1521 \\
\hline \multicolumn{6}{|l|}{ Pharmaceuticals } \\
\hline Streptokinase & 3.6 & 9.0 & NS & -5.4 & -12.0 to 1.2 \\
\hline Alteplase & 45.4 & 117.0 & NS & -71.6 & -154.6 to 11.4 \\
\hline Reteplase & 9.1 & 9.0 & NS & 0.1 & -24.9 to 25.1 \\
\hline Abciximab & 56.0 & 46.0 & NS & 10.0 & -51.0 to 71.0 \\
\hline \multicolumn{6}{|l|}{ Intervention treatment } \\
\hline Dalteparin (10 000 IU per day/placebo & 1753 & 0 & $<0.001$ & 1753 & 1587 to 1919 \\
\hline Dalteparin $15000 \mathrm{IU}$ per day/placebo & 6037 & 0 & $<0.001$ & 6037 & 5753 to 6321 \\
\hline All pharmaceuticals & 7904 & 181 & $<0.001$ & 7723 & 7518 to 7928 \\
\hline \multicolumn{6}{|l|}{ Outpatient care } \\
\hline Visits to physician & 4451 & 4410 & NS & 41 & -120 to 202 \\
\hline Visits to nurse & 259 & 276 & NS & -17 & -63 to 29 \\
\hline Visit to physiotherapist & 194 & 213 & NS & -19 & -82 to 44 \\
\hline Physician home visits & 137 & 119 & NS & 17 & -53 to 87 \\
\hline Nurse home visits & 110 & 216 & NS & -106 & -274 to 62 \\
\hline All outpatient care & 5151 & 5234 & NS & -83 & -350 to 184 \\
\hline All costs & 41744 & 35005 & 0.008 & 6739 & 1739 to 11739 \\
\hline
\end{tabular}

\section{Sensitivity analysis}

The prices reported in the costing study differed among the centres. To test the impact of different prices on the results, the minimum and maximum prices reported were applied to the cost calculations. When varying the price levels, the mean total cost range at the one month follow up was between SEK $513 \pm 3677(£ 35 \pm 250)$ and SEK $1185 \pm 2290(£ 81 \pm 156)$ per patient, which gives a cost effectiveness ratio between SEK $18300(£ 1200)$ and SEK 42300 (£2900) per avoided event.

\section{DISCUSSION}

Following one month of extended treatment with dalteparin there was a significant relative risk reduction of $47 \%$ in the combined end point of death or myocardial infarction in patients with unstable coronary artery disease, as previously reported. ${ }^{19}$ This reduction equated to a cost effectiveness ratio of SEK 30300 (range -78000 to 139000 ) (£2060, range $-£ 5300$ to $£ 9400$ ) per avoided death or myocardial infarct. Our predefined end point of death or myocardial infarction as the measure of effectiveness makes the interpretation of this ratio slightly complicated with respect to the cost effectiveness analyses, as the value of an avoided death differs from the value of an avoided myocardial infarct. Comparison with other interventions is difficult. In some similar studies the effectiveness measure has also included revascularisations, ${ }^{26}$ which complicates interpretation even further as the cost for revascularisation is in both the numerator and denominator of cost effectiveness calculations.
Ideally, the effectiveness measure should have been expressed as life years or quality adjusted life years gained. However, in the FRISC II medical trial the relatively short follow up period makes the chosen end point relevant.

A marginal increase in costs in order to avoid such a serious event as death or myocardial infarction is justified. Thus one month of dalteparin treatment is a cost effective strategy for patients with unstable coronary artery disease who are not revascularised early after hospital admission.

At the end of the three months' dalteparin treatment period there was no significant reduction in death or myocardial infarction, precluding the calculation of the cost effectiveness ratio for that period.

An invasive strategy for patients with unstable coronary artery disease has previously been shown to be cost effective. ${ }^{27}$ Owing to limited health care resources, both material and in terms of personnel, invasive procedures during the first seven days after admittance to hospital with unstable coronary artery disease are often not available. ${ }^{17}$ In cases where invasive procedures are delayed our current results show that it is clinically beneficial and cost effective to extend treatment with dalteparin while waiting for an invasive evaluation and, if appropriate, revascularisation.

\section{Conclusions and implications}

This is the first prospective economic evaluation on a large randomised trial, in which the cost effectiveness of extended dalteparin treatment has been compared with placebo in unstable coronary artery disease. All resource use was 
prospectively documented in the patients' main case report forms. During the first month of extended treatment with dalteparin there was a significantly reduced risk of death or myocardial infarction. This has now also been shown to be cost effective. Therefore, in clinically stabilised patients with unstable coronary artery disease, extended dalteparin treatment can be used as a cost effective bridge to invasive procedures.

\section{ACKNOWLEDGEMENTS}

The study was supported by and organised in collaboration with Pharmacia Corporation. The Health Research Council in the south east of Sweden also supported the research group. We gratefully acknowledge the invaluable contribution of all the patients who agreed to participate and the dedicated work of the research nurses, especially Elisabeth Logander at University Hospital in Linköping.

\section{APPENDIX}

\section{Executive committee}

L Wallentin, Uppsala (chairman); E Swahn, Linköping (co-chairman); F Kontny, Oslo; S Husted, Aarhus; B Lagerqvist, Uppsala (chairman invasive procedures committee) Elisabeth Ståhle, Uppsala (cochairman invasive procedures committee).

\section{Other members of the steering committee}

J D Nielsen, Hellerup; M Dellborg, Göteborg; O Geiran, Oslo; P Grande, Copenhagen; J Hulting, Stockholm; J Kyst-Madsen, Copenhagen; J-E Nordrehaug, Bergen; U Näslund, Umeå; H Pilegaard, Aarhus; A Rollag, Nordbyhagen; T Toftegaard Nielsen, Aarhus; H Saetre, Falun; Agneta Siegbahn, Uppsala; H Öhlin, Lund.

Other members of the invasive procedures committee M Arbeus, Örebro; H Bylund, Stockholm L Ekström, Göteborg P Eriksson, Umeå; O Geiran, Oslo; A Holmgren, Umeå; T Kellerth, Örebro; J Kyst-Madsen, Copenhagen; D Lindblom, Huddinge; B Lindvall, Huddinge; J Nordrehaug, Bergen; H Pilegaard, Aarhus; K Rådegran, Stockholm; I Sjögren, Falun; G Stenport, Linköping; E Ståhl, Lund; B Svane, Eskilstuna; R Svedjeholm, Linköping; T Toftegaard-Nielsen, Aarhus; S Y Hassan, Eskilstuna.

\section{Independent end point adjudication committee}

U Näslund, Umeå (chairman); S Persson, Malmö; K-A Jacobsson, Umeå; K Thygesen, Aarhus; G von der Lippe, Bergen.

\section{Data monitoring and safety committee}

D Julian, London (chairman); M Bertrand, Lille; H Wedel, Göteborg.

\section{Authors' affiliations}

M Janzon, E Swahn, Institution of Medicine and Care, Linköping University, Sweden

L-Å Levin, Centre for Medical Technology Assessment, Linköping University

\section{REFERENCES}

1 FRISC study group. Low-molecular-weight heparin during instability in coronary artery disease. Lancet 1996;347:561-8.

2 Klein W, Buchwald A, Hillis SE, et al. Comparison of low-molecular-weight heparin with unfractionated heparin acutely and with placebo for 6 weeks in the management of unstable coronary artery disease. Fragmin in unstable coronary artery disease study (FRISC). Circulation 1997;96:61-8.

3 Cohen M, Demers C, Gurfinkel EP, et al. A comparison of low-molecular-weight heparin with unfractionated heparin for unstable coronary artery disease. (Efficacy and safety of subcutaneous enoxaparin in non-Q-wave coronary events study group.) N Engl J Med 1997;337:447-52.

4 Fox KA. Implications of the organization to assess strategies for ischemic syndromes-2 (OASIS-2) study and the results in the context of other trials. Am J Cardiol 1999:84:26-31M.

5 Van Belle E, Lablanche JM, Bauters C, et al. Coronary angioscopic findings in the infarct-related vessel within 1 month of acute myocardial infarction: natural history and the effect of thrombolysis. Circulation 1998;97:26-33.

6 Merlini PA, Baver KA, Oltrona L, et al. Persistent activation of coagulation mechanism in unstable angina and myocardial infarction. Circulation 1994:90:61-8

7 Ernofsson M, Strekerud F, Toss H, et al. Low-molecular weight heparin reduces the generation and activity of thrombin in unstable coronary artery disease. Thromb Haemost 1998;79:491-4.

8 GUSTO Investigators A comparison of recombinant hirudin with heparin for the treatment of acute coronary syndromes. (The global use of strategies to open occluded coronary arteries (GUSTO) Ilb investigators.) N Engl J Med 1996:335:775-82.

9 PRISM Study Investigators. A comparison of aspirin plus tirofiban with aspirin plus heparin for unstable angina. (Platelet receptor inhibition in ischemic syndrome management (PRISM) study investigators.) N Engl J Med 1998;338:1498-505.

10 PRISM-PLUS Study Investigators. Inhibition of the platelet glycoprotein $\mathrm{Ilb} /$ Illa receptor with tirofiban in unstable angina and non-Q-wave myocardial infarction. (Platelet receptor inhibition in ischemic syndrome management in patients limited by unstable signs and symptoms (PRISM-PLUS) study investigators.) N Engl J Med 1998;338:1488-97.

11 PURSUIT Trial Investigators. Inhibition of platelet glycoprotein Ilb/Illa with eptifibatide in patients with acute coronary syndromes. N Engl J Med 1998;339:436-43

12 Lindahl B, Venge P, Wallentin L. Troponin T identifies patients with unstable coronary artery disease who benefit from long-term antithrombotic protection. (Fragmin in unstable coronary artery disease (FRISC) study group.) J Am Coll Cardiol 1997;29:43-8.

13 Mark DB, Cowper PA, Berkowitz SD, et al. Economic assessment of low-molecular-weight heparin (enoxaparin) versus unfractionated heparin in acute coronary syndrome patients: results from the ESSENCE randomized trial. (Efficacy and safety of subcutaneous enoxaparin in non- $Q$ wave coronary events.) Circulation 1998;97:1702-7.

14 Dunn CJ, Jarvis B. Dalteparin: an update of its pharmacological properties and clinical efficacy in the prophylaxis and treatment of thromboembolic disease. Drugs 2000;60:203-37.

15 FRISC II Investigators. Invasive compared with non-invasive treatment in unstable coronary- artery disease: FRISC II prospective randomised multicentre study. Lancet 1999;354:708-15

16 Wallentin L, Lagerqvist B, Husted S, et al. Outcome at 1 year after an invasive compared with a non-invasive strategy in unstable coronary-artery disease: the FRISC II invasive randomised trial. Lancet 2000;356:9-16.

17 Granger CB. Strategies of patient care in acute coronary syndromes: rationale for the global registry of acute coronary events (GRACE) registry. Am J Cardiol 2000:86:4-9M.

18 Fox KA, Cokkinos DV, Deckers J, et al. The ENACT study: a pan-European survey of acute coronary syndromes. European Network for Acute Coronary Treatment. Eur Heart J 2000;21:1440-9.

19 FRISC II Investigators. Long-term low-molecular-mass heparin in unstable coronary-artery disease: FRISC II prospective randomised multicentre study. Lancet 1999;354:701-7.

20 FASS 1997. Swedish drug catalogue, 1997

21 The South County Council Cooperation Committee, Sweden, 1997

22 Swedish Government. Statistical yearbook of Sweden 2001. Stockholm: Statistics Stockholm, 2001.

23 Financial Times. Currency converter. London: Financial Times, 2001.

24 Weinstein MC Siegel JE, Gold MR, et al. Recommendations of the panel on cost-effectiveness in health and medicine. JAMA panel on cost-effectiver

25 Thompson SG, Barber JA. How should cost data in pragmatic randomised trials be analysed? BM 2000;320:1 197-200.

26 van Hout BA, Bowman L, Zelinger DJ, et al. Costs and effects in therapy for acute coronary syndromes: the case of abciximab in high-risk patients undergoing percutaneous transluminal coronary angioplasty in the EPIC study. Evaluation of 7E3 for the prevention of ischemic complications. Eur Heart J 1998;19(suppl D):D59-66.

27 Janzon M, Levin L-A, Swahn E. Cost-effectiveness of an invasive strategy in unstable coronary artery disease. Results from the FRISC II invasive trial. Eur Heart J 2002;23:31-40. 